\title{
CURSO DE ENFERMAGEM DA UNIVERSIDADE ESTADUAL DO CEARÁ - A HISTÓRIA E O PROJETO POLÍTICO-PEDAGÓGICO ATUAL
}

\author{
Maria Célia de Freitas* \\ Maria Vilani Cavalcante Guedes** \\ Lúcia de Fatima da Silva***
}

\section{Resumo}

Trata-se de uma descrição dos momentos históricos do Curso de Enfermagem da Universidade Estadual do Ceará e seus reflexos no atual processo de formação profissional. Relata sobre o curso, os corpos docente e discente, assim como, acerca do seu projeto político-pedagógico. Considera, por fim, a importância deste instrumento como viabilizador da garantia da qualificação profissional.

Descritores: Projeto Político-Pedagógico; Enfermagem; Educação

\begin{abstract}
This paper describes important moments along the route of the Nursing Program at State University of Ceará and their influences on their current process of professional education. It outlines their program, their professors and students, as well as their political-pedagogical project. Finally, it highlights the importance of this instrument to warrant professional qualification.

Descriptors: political-pedagogical project; nursing; education

Title: Nursing program at State University of Ceará - its history and current politicalpedagogical project
\end{abstract}

\begin{abstract}
Resumen
Se trata de una descripción de los momentos históricos del Curso de Enfermería de la Universidad Estadual de Ceará y sus reflejos en el actual proceso de formación profesional. Hace un relato del curso y del cuerpo docente y discente, así como, sobre su proyecto político-pedagógico. Considera, por fin, la importancia de este instrumento para potenciar y garantizar la cualificación profesional.

Descriptores: Proyecto Político-Pedagógico; Enfermería; Educación

Título: Curso de Enfermeria de la Universidad Estadual de Ceará- La historia y el Proyecto Político-Pedagógico actual
\end{abstract}

\section{A história do Curso de Enfermagem da UECE}

A Universidade Estadual do Ceará (UECE), criada em 1975, é mantida pelo governo do Estado, por meio da Fundação Universidade Estadual do Ceará (FUNECE). É uma instituição multicampi que ministra cursos de graduação, nas modalidades bacharelado e licenciatura, e cursos de pós-graduação lato sensu (capital e interior), além de programa de pós-graduação stricto sensu na capital.

Dentre os cursos da área da saúde que a UECE desenvolve, o de Enfermagem destaca-se por ser o primeiro do Estado, comemorando em 2003, 60 anos. Trata-se da primeira Escola de Enfermagem do Nordeste, criada em 15 de fevereiro de 1943, com a denominação de Escola de Enfermagem São Vicente de Paulo. O reconhecimento institucional ocorreu em 26 de outubro de 1946.

Esta Escola, em 21 de janeiro de 1956, tornou-se uma unidade agregada à Universidade Federal do Ceará (UFC). Em 1975, incorporou-se à Fundação Educacional do Ceará (FUNEDUCE), como curso de Enfermagem do Centro de Ciências da Saúde da UECE ${ }^{(1)}$.

Na sua trajetória, o Curso de Enfermagem da UECE tem procurado atender às recomendações do Conselho Federal de Educação para o ensino superior no Brasil e, em especial, para o ensino de Enfermagem.

Nos últimos anos, têm ocorrido reformas, ajustes no fluxograma de disciplinas e carga horária, com o intuito de atender aos preceitos legais e propiciar formação profissional consonante com as políticas públicas de educação e saúde do Brasil.

Por exemplo, em 1982, foi preciso realizar adequações devido à proposta curricular para a Enfermagem, que procurava reordenar, acrescentar e retirar disciplinas das áreas das ciências biológicas e da saúde; humanas e sociais. Na ocasião, inseriu-se a monografia como pré-requisito parcial para a conclusão do curso.
Em outra ocasião, no ano de 1988 , foram procedidas mudanças, entretanto, nenhuma estrutural, com vistas a incluir as disciplinas da licenciatura no currículo do curso, transformando-o concomitantemente, em bacharelado e licenciatura em Enfermagem. No entanto, para atender à resolução do Ministério de Educação e Cultura (MEC), iniciouse a revisão do currículo e a elaboração do $\operatorname{PPP}^{(1)}$.

O currículo vigente, desde 1997, é disciplinar, composto de 31 disciplinas obrigatórias e 10 optativas complementares, distribuídas em nove semestres letivos. Firma um total de 4.200 horas-aulas, sendo 3.300 destinadas a aulas teóricas, teóricopráticas e ensino prático supervisionado das disciplinas das áreas temáticas e 900 horas destinadas ao estágio curricular supervisionado, nos dois últimos semestres. Este estágio é desenvolvido na rede hospitalar, ambulatorial e básica da saúde comunitária.

Atento às mudanças da atualidade, exigências das Diretrizes Curriculares Nacionais dos Cursos de Graduação em Enfermagem e Lei das Diretrizes e Bases da Educação Nacional (LDB) que no inciso I do artigo 12, determina que os estabelecimentos de ensino terão a responsabilidade de elaborar e executar sua proposta pedagógica. O nosso curso encontra-se em processo de construção e reconstrução do PPP com reuniões, oficinas pedagógicas, dialógicas e avaliativas para refletir as ações dos professores no processo ensinoaprendizagem, possibilitando repensar o papel no cotidiano da educação. O colegiado considera que o sucesso na implementação do PPP depende, em grande parte, do comprometimento dos sujeitos envolvidos no processo.

Neste curso, compreende-se PPP como uma forma de explicitar os objetivos do curso e orientar as estratégias a serem utilizadas. Mais do que um documento a ser arquivado, o PPP deve ser um instrumento de integração, de coordenação das ações dos diversos sujeitos envolvidos no processo educativo(2).

\footnotetext{
* Enfermeira. Doutoranda em Enfermagem Fundamental da Universidade de São Paulo - Ribeirão Preto. Docente da Universidade Estadual do Ceará Enfermeira do Instituto Dr. Frota.

** Enfermeira. Livre Docente da Universidade Estadual do Ceará. Doutoranda em Enfermagem da Universidade Federal do Ceará. Docente da Universidade Estadual do Ceará.

*** Enfermeira. Doutora em Enfermagem. Docente da Universidade Estadual do Ceará. Enfermeira do Hospital de Messejana.

E-mail do autor: luciadefatima.ce@uol.com.br
} 


\section{O curso e os corpos docente e discente}

Hoje, 40 professores compõem o Colegiado do Curso de Enfermagem da UECE. Eles são, na maioria, enfermeiros (37); os demais são médicos (3). Além destes docentes, ministram conteúdos relativos às ciências biológicas e da saúde, assim como, das ciências humanas e sociais, outros 18 professores não pertencentes à estrutura de Colegiado do Curso, que pertencem aos demais colegiados dos cursos da área das Ciências da Saúde.

Do total de professores que pertencem ao colegiado do Curso de Enfermagem da UECE, 10 são doutores, 2 livredocentes, 26 mestres e 2 especialistas. Dos mestres, 4 encontram-se realizando cursos de doutoramento. Merece destacar que 31 professores pertencem ao corpo docente permanente da UECE (9 na modalidade dedicação exclusiva, 1 na de 20 horas semanais e os demais na de 40 horas semanais) e 9 são contratados temporariamente, por meio da modalidade professor substituto. Os docentes são distribuídos nas atividades de ensino teórico, teórico-prático e estágios supervisionados do Curso de Graduação.

O corpo discente é constituído por 412 alunos distribuídos nos 9 semestres da grade curricular do curso. Estes alunos são admitidos por meio de processo seletivo com entrada semestral de 35 vagas. Além destes ingressos, quando da existência de vagas, admitem-se também alunos advindos de transferências de outras universidades e graduados. Ressalte-se que os graduados têm formação em áreas como Fisioterapia, Medicina Veterinária, Farmácia, Psicologia, Terapia Ocupacional, Odontologia e Fonoaudiologia.

Aos alunos são oferecidas vagas de bolsista de pesquisa na qualidade iniciação científica, seja da Universidade, seja do Programa Interinstitucional de Bolsas de Iniciação Científica (PIBIC) do CNPq e Fundação Cearense de Apoio ao Desenvolvimento Científico e Tecnológico (FUNCAP). Eles também dispõem de 12 vagas do Programa Especial de Treinamento (PET) do MEC. Além disso, a UECE lhes oferece bolsas de extensão, na modalidade bolsa de trabalho.

\section{Projeto Político-Pedagógico: análise documental}

O PPP representa os anseios de educadores e educandos de um curso, voltados para o contexto e necessidades de elaborar estratégias que fundamentem e orientem ações interdisciplinares, tendo como predomínio o interesse de autonomia profissional para agir e interagir, segundo a realidade e demanda da população. Tem como base teorias pedagógicas que consideram a interação entre o curso e o contexto geral em que se insere e traz em sua concepção um compromisso, definido no coletivo.

Um projeto educativo pode ser tomado como promessa frente a determinadas rupturas. As promessas tornam visíveis os campos de ação possível, comprometendo seus atores autores $^{(3)}$. Para seus professores e alunos o PPP do Curso de Enfermagem da UECE é um constante desafio à construção e à reconstrução.

As primeiras intenções explicitadas, demonstradas na proposta atual, permitem identificar que este adota como parâmetros a LDB da Educação Nacional, nº 9394/96, as recomendações dos Seminário Nacional de Diretrizes para a Educação em Enfermagem no Brasil (SENADEn), Lei do Exercício Profissional, a Carta de Florianópolis (documento construído durante a reunião nacional de cursos de enfermagem, ocorrida por ocasião do $51^{\circ}$ Congresso Brasileiro de Enfermagem, 1999) e as Diretrizes Curriculares Nacionais dos Cursos de Graduação em Enfermagem, aprovado em agosto de 2001, do Conselho Nacional de Educação/Câmara de Educação Superior.

O PPP destaca como missão, formar enfermeiros com compreensão científica, técnica, política e ética, capazes de intervir no processo saúde-doença do ser humano, numa perspectiva crítico-transformadora voltada para o cuidar, o educar, gerenciar e pesquisar, caracterizando interesses técnicos, práticos e emancipatórios. As ações desses profissionais devem se interrelacionar com os demais trabalhadores da saúde, nos diferentes níveis de complexidade dos serviços do Sistema único de Saúde (SUS), tanto na instituição hospitalar, quanto ambulatorial, comunidade e familiar(1).

A proposta apresenta os marcos filosófico e conceitual, expressando a compreensão geral de crenças e valores, bem como, os conceitos de sociedade, saúde, homem, enfermagem, enfermeiro, assistir em enfermagem, prática educativa de enfermagem, processo saúde-doença, educador e educando.

\section{Os marcos teóricos do projeto político-pedagógico}

O marco é uma fronteira, limite daquilo que se pretende desenvolver ou realizar no âmbito do conhecimento e da ação. No que se refere à Enfermagem, é necessário que, através do marco, se possam identificar os significados favoráveis às buscas da profissão e ao processo de formar enfermeiros para o presente e o futuro(4)

$\mathrm{Na}$ proposta do projeto pedagógico estão ressaltados os marcos filosófico, conceitual e estrutural. As concepções filosóficas representam crenças e valores da comunidade envolvida na proposição e desenvolvimento do PPP, os pressupostos ou princípios éticos-filosóficos que orientam a caminhada e re-direcionam os rumos da profissão. Em relação ao conceitual, este se refere aos fundamentos teóricos, conceitos construídos por seus propositores e/ou estabelecidos por pensadores, tanto da área da profissão como outra, desde que mantida a correlação com os demais marcos(4)

O conjunto de definições e conceitos interrelacionados, que representam o marco conceitual do PPP, focaliza o homem, o enfermeiro, educador, educando, enfermagem, processo saúde-doença, prática educativa, assistir em enfermagem, sociedade. Tais conceitos representam o compromisso do curso e do projeto com a formação de profissionais competentes para desenvolver sua práxis segundo o contexto vivido.

Em relação ao marco estrutural, estão incluídas a composição e organização curricular, com seus requisitos e pré-requisitos, sua distribuição no tempo conforme normalização a ser obrigatoriamente seguida, definições de ementas, elaboração dos planos de ensino de disciplinas, o planejamento, a implementação de estratégias com novos olhares em direção ao processo ensino-aprendizagem, bem como a avaliação, formativa e somativa.

\section{Perfil do enfermeiro da UECE}

O Curso de Enfermagem da UECE pretende formar profissionais que desenvolvam a práxis comprometidos com as necessidades de saúde da população, revelando em seu desempenho competência, autonomia, iniciativa, ética, racionalidade crítica e reflexiva para solucionar os problemas oriundos do trabalho na equipe multidisciplinar, e em especial da profissão.

O curso forma enfermeiro bacharel generalista, com perfil crítico e reflexivo, capaz de avaliar o ser humano em suas fases de desenvolvimento, ou cursos de vida, e no processo saúdedoença, intervindo segundo suas peculiaridades, no perfil epidemiológico nacional, nas políticas sociais e de saúde, articulando com as práticas de enfermagem, reconhecendo as dimensões biopsicossociais e seus determinantes, identificando e compreendendo os fenômenos de enfermagem, intervindo e avaliando os resultados, com autonomia e competência(1).

Nesse sentido, o perfil do profissional competente, destaca-se como aquele capaz de atuar em múltiplas áreas, compreendendo a natureza humana nas diferentes expressões e fases evolutivas, utilizar a ciência/arte de cuidar como 
instrumento de interpretação que garanta a qualidade do cuidado e da assistência; trabalhar em equipe; identificar as necessidades individuais e coletivas de saúde da população e seus determinantes; gerenciar o processo de trabalho de enfermagem nos âmbitos de atuação profissional; organizar e dirigir programas de qualificação contínua dos trabalhadores de enfermagem; participar da administração da instituição em que atua; utilizar as novas tecnologias em benefício do cuidar do indivíduo, família e coletividade; conhecer os deveres e os dilemas éticos da profissão; desenvolver, aplicar e participar de pesquisas e outras formas de produção de conhecimento que objetivem a qualificação profissional e manter-se em contínuo processo de formação(1).

Compreende-se o profissional com perfil generalista aquele capaz de se inserir no mercado de trabalho, realizando reflexão crítica, com compromisso científico, ético, social, e político, diante da realidade sanitária, intervindo sobre os problemas e situações de saúde e doença mais prevalentes, enfatizando as dimensões biopsicossociais dos seus determinantes ${ }^{(5,6)}$.

A construção de competências expressa nas Diretrizes Curriculares Nacionais, depende do equilíbrio entre o trabalho isolado de seus diversos sujeitos e a integração destes em situações de operacionalização de procedimentos. A dificuldade didática está na gestão dialética, dessas duas abordagens. É utopia, porém, acreditar que o aprendizado seqüencial de conhecimentos provoca espontaneamente a integração operacional em competências ${ }^{(7)}$.

Portanto, essa construção de conhecimentos deve ser pautada nos valores socioculturais e nos pressupostos teóricometodológicos voltados não apenas para a qualificação e competência do profissional para ações de cuidar, mas também, para a formação de profissionais comprometidos com o exercício do saber do cotidiano de maneira crítica e participativa, com indivíduos, famílias e comunidade.

Dessa forma, o PPP explicita os interesses citados, focalizando o processo saúde-doença da população, na realidade voltada à assistência integral do homem, na perspectiva clínica, epidemiológica e cultural. Este enfermeiro deverá ser capaz de compreender a realidade de saúde da população e contribuir para o desenvolvimento da profissão(1).

Percebeu-se na análise do PPP que sua proposta, identificada pela missão, objetivos, currículo do curso, prioriza um compromisso com a construção de conhecimentos fundamentados e interligados a interesses técnico, de consenso e emancipatório, uma vez que tenta articular e valorizar a formação de profissionais aptos a atuarem nos problemas de natureza específica e geral, como resultado do saber sobre o processo saúde-doença da comunidade.

Essas dimensões da vida representada pelo interesse técnico envolvem a razão instrumental e demonstra estratégias para guiar as ações e exercer o controle. Inclui conhecimentos gerais e específicos valorizando a habilidade psicomotora e o domínio de procedimentos técnicos, tais como, punção venosa, cateterismo, sondagens, entre outros; pelo interesse de consenso, orientado pela racionalidade centrada no entendimento.

$O$ interesse de consenso privilegia a habilidade de interação, valoriza a interdisciplinaridade no cotidiano da educação e posteriormente nas atividades profissionais. Envolve a participação ativa de educadores e educandos de ensino-aprendizagem e valoriza as experiências; e pelo interesse emancipatório, que se preocupa em envolver o educando com a realidade social e política, articulando conhecimentos que possibilitem desenvolver o pensamento crítico, reflexivo e argumentativo. Fundamenta-se no conhecimento da realidade populacional, política e social. O processo ensino-aprendizagem enfatiza pensar, articulando conhecimentos e contextos da prática profissional.
Assim, é inegável a influência que o cenário sócio-político exerce sobre o ensino, no âmbito das políticas educacionais e, na relação entre as pessoas envolvidas especialmente no relacionamento entre professor e aluno; influência esta que pode ser considerada fundamental em qualquer processo de formação.

\section{Considerações Finais}

A elaboração do PPP de um curso, apesar de se constituir em um processo laborioso que requer disponibilidade $\mathrm{e}$ compromisso de docentes e discentes, caracteriza-se como um instrumento que norteia todo processo ensinoaprendizagem, permite a avaliação continuada e, por isso, contribui para a garantia da qualidade da formação profissional.

O compromisso com a formação de enfermeiros competentes, cônscios das responsabilidades inerentes ao saber-fazer, exige dos educadores acompanhamento constante dos limites e possibilidades postos pelo contexto acadêmico, profissional e social, ao longo do processo de formação, vislumbrando o movimento dinâmico do curso da vida dos aprendizes do cuidado de pessoas, levando-se em consideração o processo saúde-doença.

Assim, pensa-se que o PPP não deve ser elaborado visando apenas o espaço onde se realiza o curso, a universidade, mas procurar implementar conteúdos que se voltem a realidade local, do país para que o profissional formado possa resgatar conhecimento que o permita exercer a práxis articulando os conceitos postos no projeto.

Construir um PPP para os dias atuais exige atenção às mudanças na sociedade, comunidade em que se referencia que permitem perceber a ação humana, principalmente no tocante ao modelo de formação que se adota, a necessidade de contrapor os conhecimentos adquiridos e o agir profissional, demandas e expectativas de desenvolvimento do setor saúde, em determinadas situações-problemas do cotidiano favorecendo o exercício da autonomia profissional.

Portanto, o PPP vai além de um simples documento para cumprir as exigências burocráticas. Ele deve ser construído para ser vivenciado em todos os momentos, por todos os envolvidos com o processo de formação do curso e instituição e deve ser expresso pelos interesses orientadores da construção do conhecimento que deve se preocupar com a realidade local e todo país.

\section{Referências}

1. CCS. Projeto político pedagógico. Fortaleza (CE): Centro de Ciências da Saúde, Universidade Estadual do Ceará; 2002.

2. Saupe R, Geib LTC. O processo de construção dos projetos políticopedagógico na enfermagem. Revista Eletrônica de Enfermagem [periódico on line]. Goiânia (GO) 2001;3(2). Disponível em: URL:http:/ /www.fen.ufg.br/revista. Acessado em: 20 jul 2003.

3. Gadotti M. Pressupostos do projeto pedagógico. In: Anais da Conferência Nacional de Educação para Todos; 1994, Brasília (DF), Brasil. Brasília (DF): MEC; 1994.

4. Saupe R, Alves ED. Contribuição à construção de projetos-políticos pedagógicos na enfermagem. Revista Latino-americana de Enfermagem, Ribeirão Preto (SP) 2000;8(2):60-7.

5. Takahashi OC. Currículo do curso de enfermagem. Londrina (PR): Universidade Estadual de Londrina; 1995.

6. Carta de Florianópolis: enquadramento das diretrizes curriculares. In: Anais do $51^{\circ}$ Congresso Brasileiro de Enfermagem, e $10^{\circ}$ Congreso Panamericano de Enfermería; 1999 out 7; Florianópolis (SC), Brasil. Florianópolis (SC): ABEn; 1999.

7. Perrenoud P. Construindo as competências desde a escola. Porto Alegre (RS): ARTMED; 1999.

Data de recebimento: 30/08/2003

Data de aprovação: 28/10/2003 